\title{
ICCPP Student Workshops: Intercultural Transdisciplinary Learning in Practice
}

\author{
Koen De Wandeler ${ }^{1}$ \\ KU Leuven - University of Leuven, Belgium \\ Faculty of Architecture \\ ${ }^{1}$ koen.dewandeler@kuleuven.be
}

\begin{abstract}
In the past two years, the Department of Architecture of the University of Moratuwa (UoM) in collaboration with the Faculty of Architecture of KU Leuven (Belgium) has organized international student workshops as part of the International Conference titled 'Cities, People and Places' (ICCPP workshops). These well-attended events offered bachelor and master level students of UoM and other universities in Sri Lanka and abroad an opportunity to experiment with a practice-based research approach towards architecture and urban design. This involved a conceptual and methodological framework that put the students who supplied base-line fieldwork material interchangeably in the roles of researchers, clients and designers. In addition, the exercise sharpened intercultural awareness and exchange as local and foreign students mingled in working on widely diverging case studies gathered in Sri Lanka and abroad.

This paper outlines the conceptual framework of this initiative and the format developed in view of the workshop objectives. It then reviews how the first of these workshops was initiated, prepared, and conducted. Next, it critically assesses the envisaged outcomes in terms of concepts, methods, logistics and learning processes. Final reflections outline the lessons learnt in view of participants' responses. It is proposed to further elaborate this experimental approach as part of the ICCPP events and possibly apply it to other similar initiatives.
\end{abstract}

Keywords: intercultural exchange, trans-disciplinarity, research-by-design, architectural and urban design education

\section{Introduction}

Cities have always been in constant flux. Contemporary cities are even more so because of what Marsh (2013) coined "the fifth industrial revolution". This "revolution" cannot be associated with a single new technology, and requires a convergence of technological advances, organizational behavior and global 
International journal on Urban Environnements

connections that has changed how the world works. Marsh (2014) contends that this new era is about the "3 Cs" i.e., "connections, creativity and customization" and above all, about the convergence between these three. Internet, wireless communication, digital media and a variety of open source social software are greatly contributing to this convergence: they have prompted the development of horizontal networks of interactive communication that connect local and global fields of action at any time.

With the demise of mass production in manufacturing and mass communication in media came the closing stages of stereotype, blue-print thinking in architecture, planning and design. In line with new trends of flexibility and interactive multimodal exchange, spatial planners and designers-once the pioneers of the modernist utopiabegan heeding the demands of an increasingly vocal clientele and an ever more complex set of administrative, financial and regulatory frameworks. Professional practice nowadays entails a wide variety of capabilities including social responsibility and political correctness, interpersonal skills, networking and management skills, computer literacy, as well a solid dose of business acumen.

Changed working conditions triggered a critical review of conventional education models. Practitioners, academics and students have tested alternative forms of collaboration and developed innovative approaches that help students acquire the skills and competences necessary to meet the current and future challenges of the profession. One of the ways tried at the Faculty of Architecture of the KU Leuven, was to develop modules that sought to expose students to daily realities outside the class room. The ICCPP workshops serve a similar objective: they offer undergraduate and graduate students a lived experience of intense horizontal collaboration across disciplinary and socio-cultural boundaries.

This paper critically reviews the first experiment in this series of yearly workshops. It outlines the conceptual framework underlying this initiative and the workshop format developed in view of the workshop objectives. It then clarifies the theoretical and methodological basis of the 2013 ICCPP workshop and describes the case studies drafted on the basis of pre-workshop fieldwork as well as the outputs produced in the course of the one-day workshop. The next section critically assesses whether the conceptual framework proved relevant, the methodological guidelines effective, the logistics efficient, and the learning process successful? The final section reflects on lessons learnt and ways to take this experimental approach forward as part of coming ICCPP events.

\section{Conceptual framework}

The changing modalities of project planning and implementation, along with the repeated economic crises over the past decades, have lead architectural and urban practitioners to integrate transience and temporality into their design and planning practice. In parallel, spatial designers have shown a growing concern about the environmental and ethical dimensions of their profession. Inspired by phenomenological thinking, this self-reflection involved an increasing awareness about concepts like 'interpretation', 'lived experience', 'place' and 'life-world'. Philosophical considerations concurred with debates revolving around participation and user involvement in the creative process of spatial design. Synergy between these 
reflective processes triggered inter, multi, and transdisciplinary efforts to transcend narrow professional confines.

Trans-disciplinarity transcends disciplinary boundaries by encouraging inputs by lay-people who previously had never been taken seriously in research or professional practice. It implies a hybridization of knowledge and modes of inquiry offering "a critical and self-reflexive research approach that relates societal with scientific problems" (Jahn et al.,2012;8). It integrates discipline and profession, theory and practice, as well as the ethical dimension and the inextricable 'being-in-the-worldness' of architecture and planning praxis (Harries, 1997; Doucet \& Janssens, 2011;2). According to Hirsch Hadorn $(2008 ; 431)$, this approach qualifies "when knowledge about a socially relevant problem field is uncertain, when the concrete nature of problems is disputed, and when there is a great deal at stake for those concerned by problems and involved in dealing with them".

This inherently problem-oriented character has been a 'leitmotif' in conceptualizing and elaboration of the ICCPP-workshops. It concurred with concerns about students to avoid fieldwork and rely almost exclusively on digitally accessed data and software packages. The workshop format therefore emphasized face-to-face interaction during preliminary fieldwork as well as throughout the workshop day itself.

\section{Workshop format}

The ICCPP workshop format revolves around pre-workshop fieldwork which provides the base-line material that is further elaborated during the workshop itself. Participants are predominantly but not exclusively students in architecture and urban design disciplines. In the course of the exercise, participants who did the fieldwork interchangeably assume the roles of researchers, clients and designers. Other participants get to experiment with practice-based research and design. All participants -whether they are local and foreign students, coaching academics or practicing professionals-get to mingle and thus have an opportunity to sharpen their interdisciplinary and intercultural awareness and communication skills.

Given the importance of base-line field work material, organizers needed to start preparations several months in advance. As soon as the workshop's theme was known, they needed to identify colleagues who were interested in the approach and willing to supervise a group of students during the pre-workshop fieldwork. To consolidate the partnership, supervisors and their students were supplied with background and reference materials clarifying the theoretical and conceptual framework of the workshop. Organizers also provided all groups with precise methodological guidelines and instructions on how to proceed in the field and the processing of the field-data. Field researchers were asked to compile all crucial documents, jottings, sketches or other graphic materials gathered during the fieldwork. Based on these materials, they then prepared a comprehensive presentation that situated the fieldwork site in their home town, outlined observation methods and techniques and summarized the findings.

The workshop took off with an introduction of the main theme and fieldworker teams presenting their respective case studies to the assembled audience of students and coaching lecturers. After this, workshop dynamics proceeded following the sequence of interactions between fieldworkers and other participants illustrated in Figure 1. 


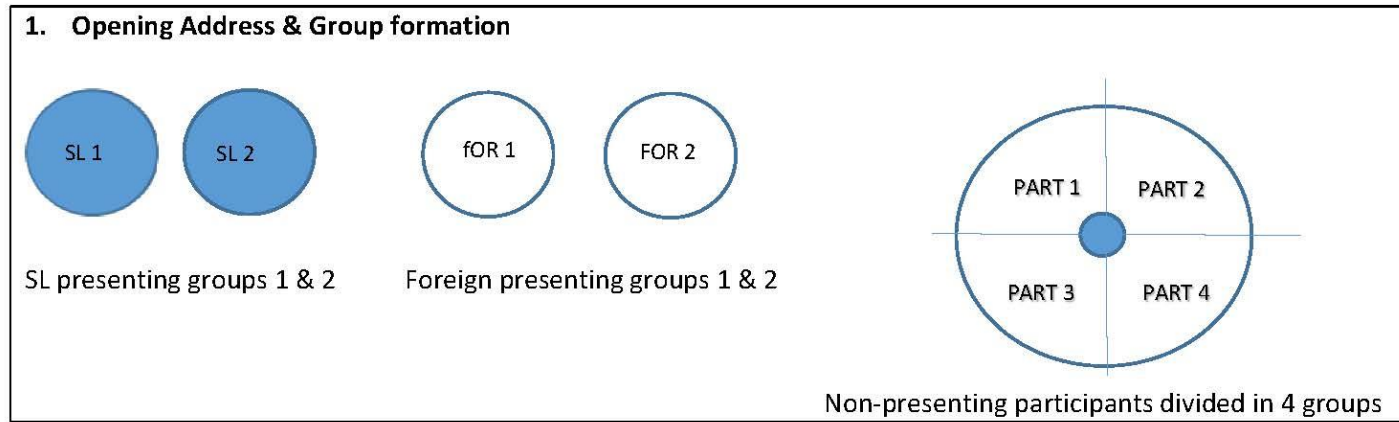

\section{Consultation:}

Each group of participants consults one of the presenting groups: asks for additional data, background info, etc.
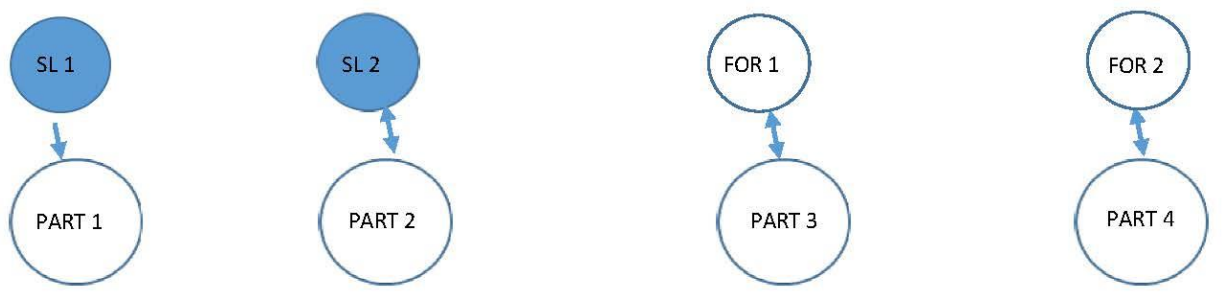

Part 1 consults SL 1

Part 2 consults SL 2

Part 3 consults FOR 1

Part 4 consults FOR 2

\section{Brainstorming:}

Each group of participants is joined by a presenter group (other than the one it consulted) and together, they determine key issues and rank priorities (15 mins. break in between at leisure)

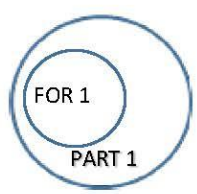

FOR 1 joins Participants 1

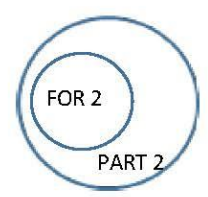

FOR 2 joins Participants

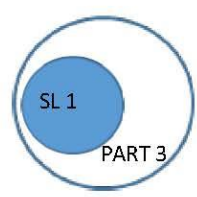

SL 1 joins Participants 3

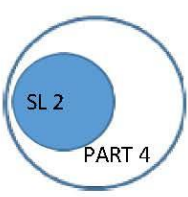

SL 2 joins Participants 4

N.B.: Steps 4 and 6 adopt the configuration of (3) brainstorming; step 5 that of (2) consultation

\section{Scenario-building:}

Each group of participants (including presenters/fieldworkers) elaborates one or more scenarios to invigorate social resilience and divert/alleviate/remedy the imminent crisis

\section{Consultation and feedback:}

Each group of participants submits the elaborated scenarios for comments and feedback to the presenters' group it initially gained information from (same configurations as 2 ).

\section{Fine-tuning:}

Each group of participants (including presenters/fieldworkers) fine-tunes its most feasible scenario and projects an urban / architectural design framework.

\section{Presentations and comments:}

Each group of participants presents a scenario and urban/ architectural design framework for their case study to the assembly of presenters who did the initial fieldwork, other participants and coaches. Feedback and comments from the audience lead to final reflections.

Fig. 1: Schematic outline of ICCPP student workshop dynamics 
International journal on Urban Environnements

This sequence put fieldworkers interchangeably in the roles of researchers, clients and designers. Other participants were subdivided in as many groups as there were components in the case studies. Each group of participants then focused on one component throughout the workshop. In the first instance, each group would ask the presenters/fieldworkers for additional data and background information on the case study. In the next step, fieldworkers could join any one group except the ones that were working on the case they had presented. Strengthened by the lived experience of the fieldworkers, each group then would launch into a practice-based research and design process. They first brain-stormed on the case-study, then identified key issue(s) to address, and then started to elaborate and fine-tune a scenario addressing these issue(s). The field workers would re-assume a 'client' role in between the scenario building and the fine-tuning phases as well as during the final presentations. As the final presentations were held for a full assembly, all students and coaching lecturers could learn from the various approaches taken in different contexts, as well as provide feedback and comments.

\section{Introduction: Henri Lefebvre's rhythm-analysis}

This workshop dealt with the transience of urban realities: it aimed to make students aware of time as a fourth dimension of place-making. Given the emergence and multiplication of various forms of 'temporary urbanism' (Bishop and Williams, 2012), the workshop created an opportunity to explore drivers and conditions of this trend and gauge its impact on research and design. Lefebvre's writings $(1995,2004)$ provided participants with a theoretical framework to explore the added value of 'rhythm-analysis' in researching and re-designing public places in function of their usage over time.

According to Lefebvre $(2004 ; 15)$, rhythm occurs whenever there is interaction between a place, a time and an expenditure of energy. Nowadays, this interaction is governed by clock-wise regulated time: a complex of rational rhythms overshadows the multiple natural rhythms of the body (respiration, heartbeat, hunger and thirst, etc.). Rhythm-analysis was presented as "a science, a new field of knowledge [savoir]" (Lefebvre, 2004;3) that created the possibility of opening and unwrapping these distinct but intimately entwined bundles of rhythm. Lefebvre professed that rhythm was a mode of analysis: a tool rather than just an object of analysis: rhythm-analysts had to draw on lived experience and adopt a transdisciplinary approach bringing together widely diverse practices and types of knowledge.

\footnotetext{
'More sensitive to times than to spaces, to moods than to images, to the atmosphere than to particular events, [the rhythm-analyst] is strictly speaking neither psychologist, nor sociologist, nor anthropologist, nor economist; however he borders on each of these fields in turn and is able to draw on the instruments that the specialists use. He therefore adopts a transdisciplinary approach in relation to these different sciences. He is always 'listening out', but he does not only hear words, discourses, noises and sounds; he is capable of listening to a house, a street, a town as one listens to a symphony, an opera.'
}

Lefebvre, H., 2004;87-88. 
International journal on Urban Environnements

The pre-workshop fieldwork guidelines therefore introduced a methodology that was not 'analytic' in a strictly positivistic or scientific sense of term, but rather sided with the 'lived experience' comparable to participant observation in anthropology (Highmore, 2005;150). Guided by identical theoretical background information and methodological guidelines, Asst. Prof. Supriya Kukreya (S.P.A. Bhopal), Prof. Dr. Ranjana Mittal (S.P.A. New Dehli) and Dr. Janaka Wijesundara (MUD, UoM) supervised students' fieldwork in a public place of their choice. The main criterion for the selection of a site was that it was a place where travelers, white and blue-collar employees, vendors, customers and their activities mingled and kept shifting over time. After scouting the site and establishing on-going activities, the students identified appropriate times and positions to chart peoples' usage of the place through rhythm-analytical observations (i.e. measuring the time-space dimensions).

\section{Case-study 1: Nehru Nagar Junction in Bhopal}

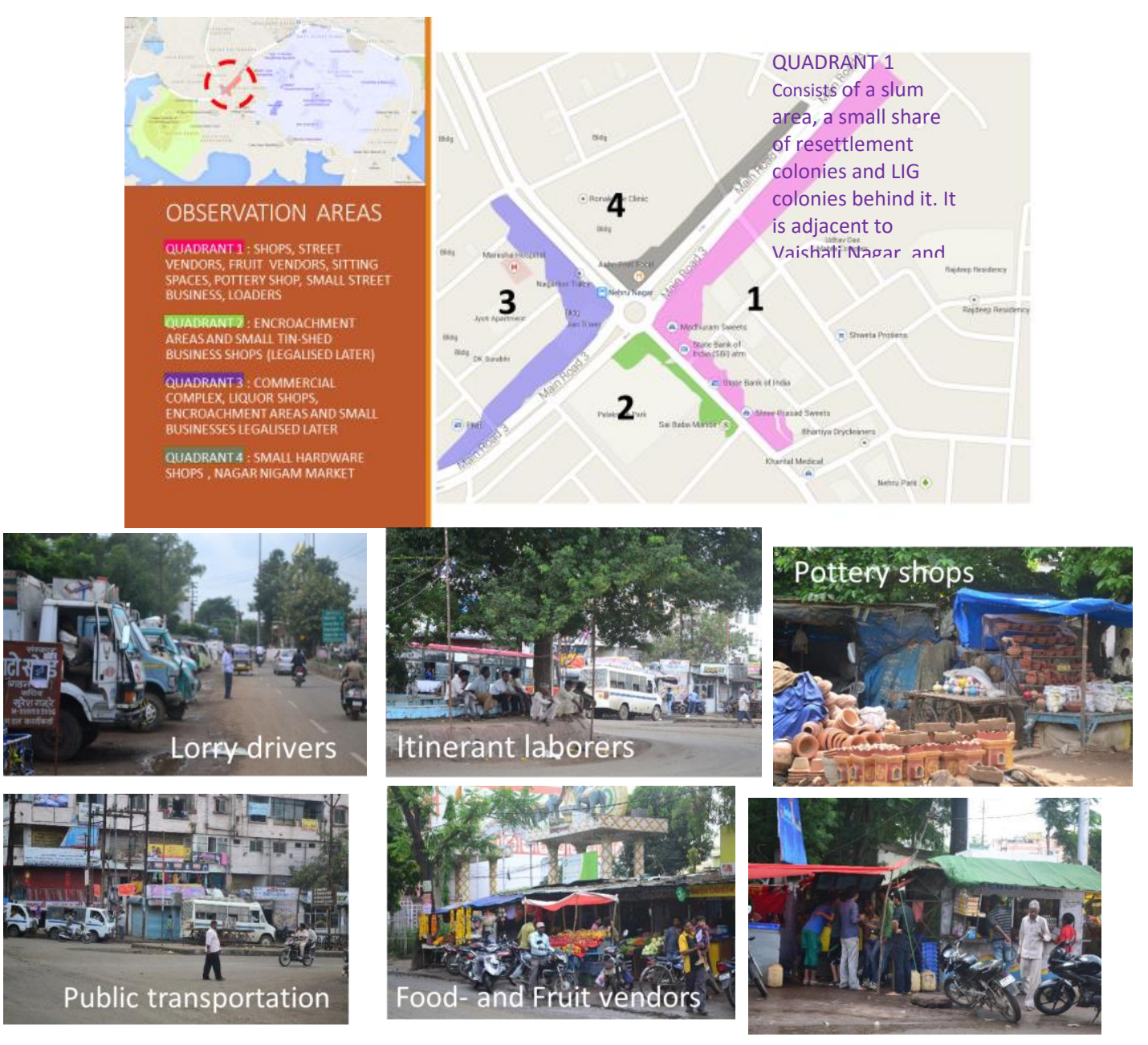

Fig. 2: Bophal fieldwork: situation and summery overview of Nehru Nagar junction. Source: Asst.Prof. Supriya Kukreya and fieldwork team from S.P.A. Bhopal, India 
International journal on Urban Environnements

The Bophal case study focused on the Nehru Nagar roundabout which is a public transportation hub and one of the busiest junctions in the city. It is situated between two major educational institutes and surrounded by residential settlements for a variety of income groups. Fieldworkers subdivided the site into four quadrants and associated each quadrant with residential types and commercial activities as illustrated in Figure 2.

Fieldworkers' observations revealed that trading businesses had spread out from the Nagar Nigam market and diversified into a wide range of informal activities. As shops encroaching on road-side land became legalized, make-shift sheds selling pottery ware and motorcycle repair shops multiplied. The area became ever more crowded with shopkeepers and their customers, market suppliers, lorry drivers waiting to load their goods, itinerant laborers waiting to be picked for a day's work, as well as students and commuters waiting for a bus. Drawn by such wide array of customers, various swarm of hawkers flocked to the area at different times of the day.

In the workshop, participants assigned to this case quite naturally identified the wide variance of rhythms as root cause for the chaotic development of the junction. Randomly parked vehicles and swarming crowds obstructed traffic flows. The line-up of pushcarts, make-shift shops and shop-houses encroached on walkways, jammed pedestrian mobility and pushed the residential areas behind the shops into a stifling insularity. The workshop process lead to a design strategy that aimed to alleviate overall congestion of the junction. It proposed to plant trees that would provide shade along the roadside, make random parking more difficult and thus create a more pleasant environment for all pedestrian users of the place. In addition, it proposed to increase the permeability of the roadside buildings. To achieve this, ground-floor sections of the road-side would be opened up, selected commercial functions would be brought to the first floor and building heights would be increased accordingly.

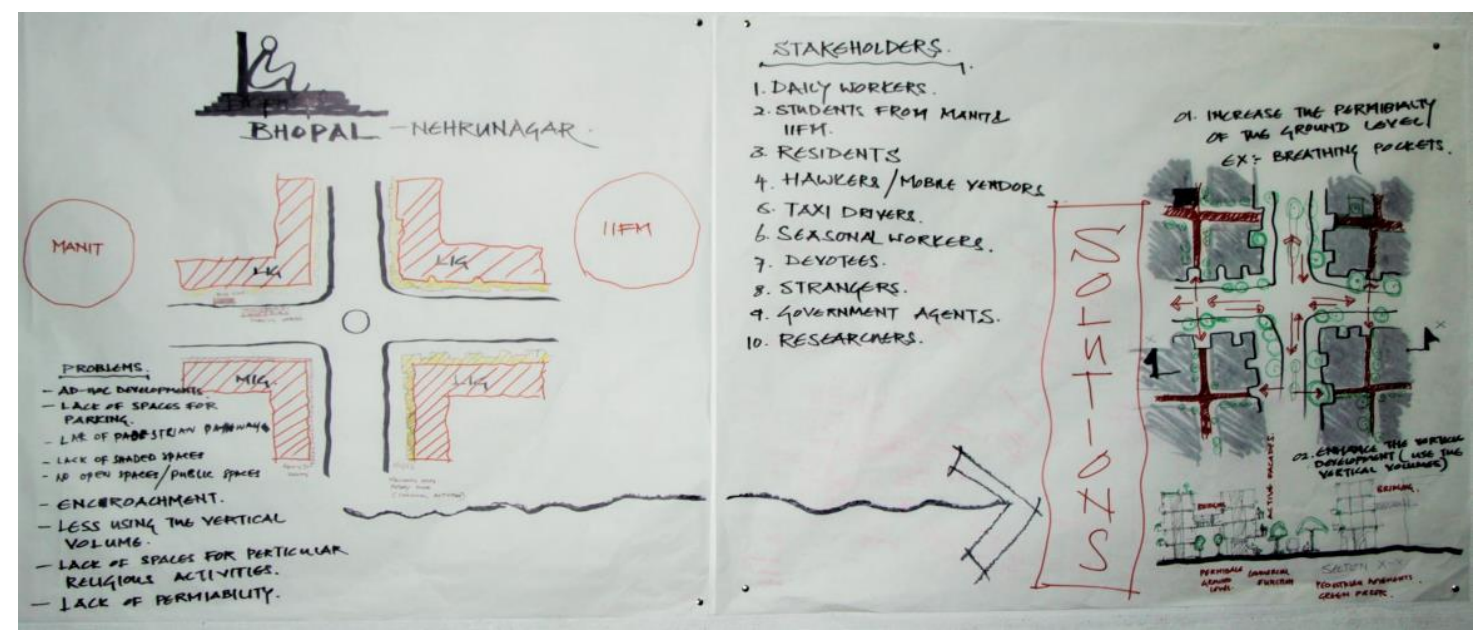

Fig. 3: Issues and design strategy elaborated for the Bhopal case Source: ICCPP2013 workshop participants 
International journal on Urban Environnements

\section{Case-study 2: Community Center of the New Friends Colony in New Dehli}

The student team in New Dehli chose to work on the community center of the New Friends Colony in South New Dehli. This affluent residential neighborhood is well connected by road and rail and not too far from the airport. The community center is a pedestrian area where banks and offices side with famous beauty salons and popular retail stores, pubs, fast food outlets and restaurants. Since the center is situated near major educational institutions, it attracts a lot of young people, especially during weekdays. However, the team could gather to conduct fieldwork only on Sundays, when many outlets were closed and street-vendors invaded the scene.

The team split up and made field observations from three distinct spots: one near the center's parking lot, one in its central pedestrian street and one on the central square. At each spot, one fieldworker observed shopkeepers (stationary), another one the activities (varying) and a third one the passers-by. As demonstrated by the activity chart shown in Figure 4, annotations were not limited to circulation pathways and interaction patterns, but also monitored overall atmosphere as well as individual mood of places and people.

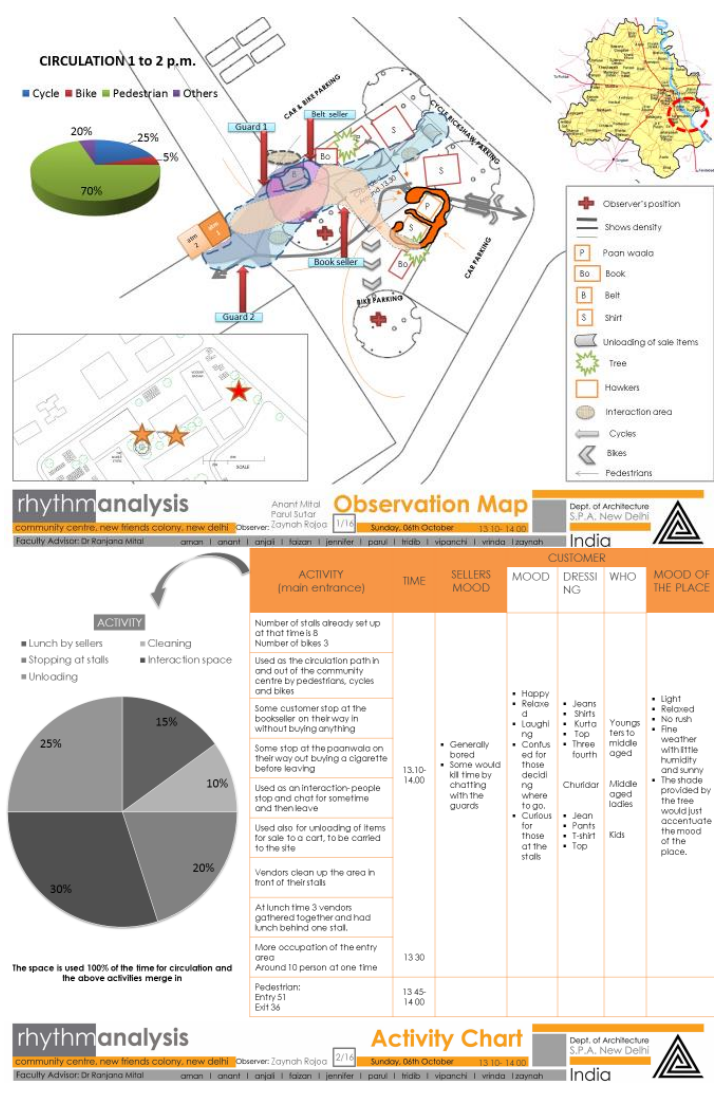



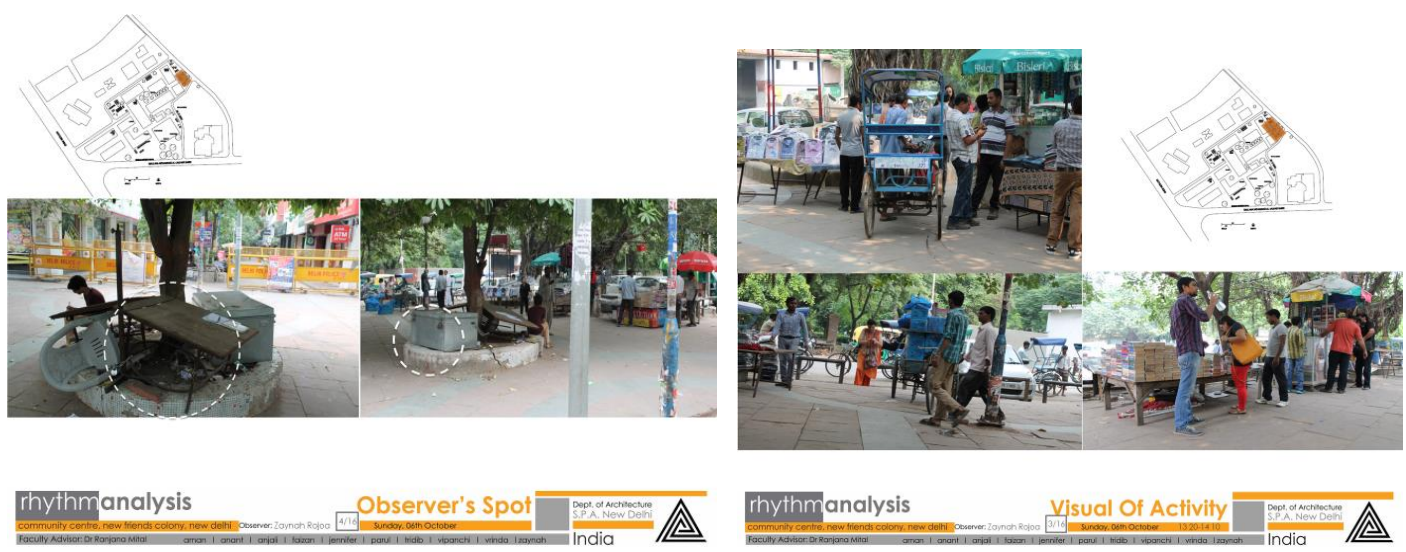

Fig. 4: Overview of observations at one observation point, early afternoon

Community Center, New Friends colony, New Dehli

Source: Prof. Dr. Ranjana Mittal and fieldwork team from S.P.A. New Dehli, India

Participants who dealt with this case were duly impressed by the accuracy and detail of the observations. The observed activities and rhythms did not indicate the need for major adjustments in the overall lay-out of the community center. In the absence of the usual crowd, and with most of the store-fronts shuttered, fieldwork observations unwittingly drew attention to the overall desolation and untidiness of the pedestrian space and the impassiveness of its users.

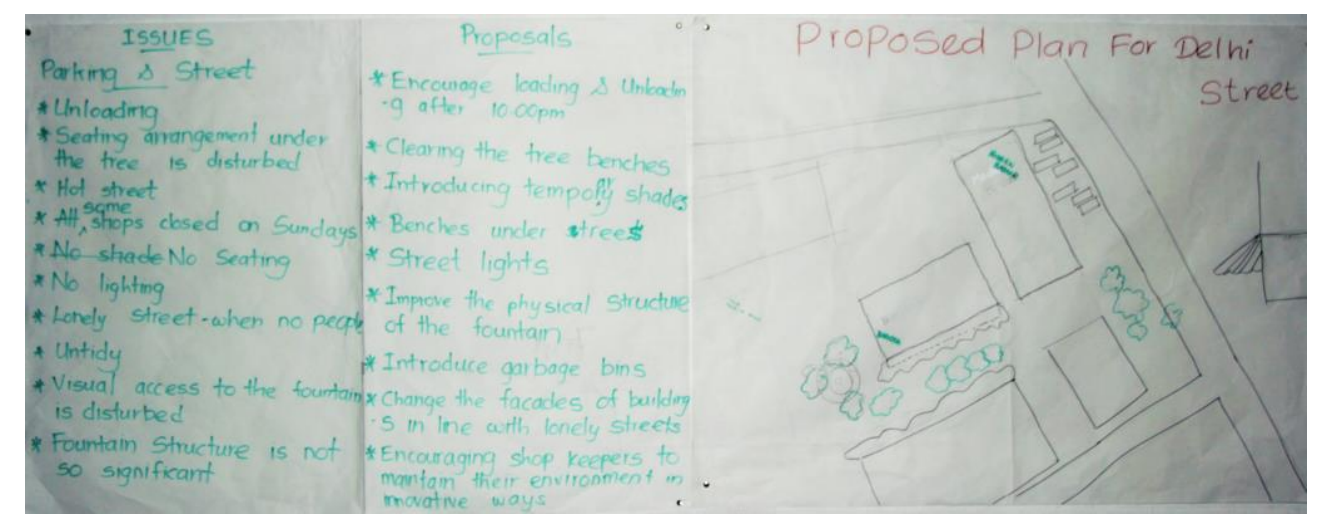

Fig. 5: Issues and design strategy elaborated for the New Dehli case Source: ICCPP2013 workshop participants

As shown in Figure 5, workshop participants identified a number of issues which seem to be symptomatic for many public spaces that have not genuinely been appropriated: poor shading and deficient street lighting, broken pavements and neglected seating arrangements and a gauche attempt to articulate the center's fountain as an attractive landmark. Proposals addressed all of these short-comings in the hope that passers-by would linger on well-maintained benches in the shade of trees and canopies to enjoy snacks, a good read and good company. These piecemeal interventions may not amount to much of a design strategy, but at least, they increase 
International journal on Urban Environnements

the chances that the community center is experienced as a place where it is good to dwell and meet other people.

\section{Case-study 3: Fort Railway Station in Colombo}

In Colombo, students focused on the vicinity of Fort Railway Station. The Station is one of many prominent buildings with historical significance in the Fort area. It is the country's main railway node and functions as a gateway into Colombo City and regional bus terminals are situated in the immediate vicinity of the station. Fort, like any other transportation hub, attracts a large variety of commercial activities including well-established outlets in Pettah, makeshift road-side shops opposite the station, as well as peddlers of all sorts. In addition, many daily wage laborers and unemployed people seeking for a day's earnings crowd the area every day of the week.

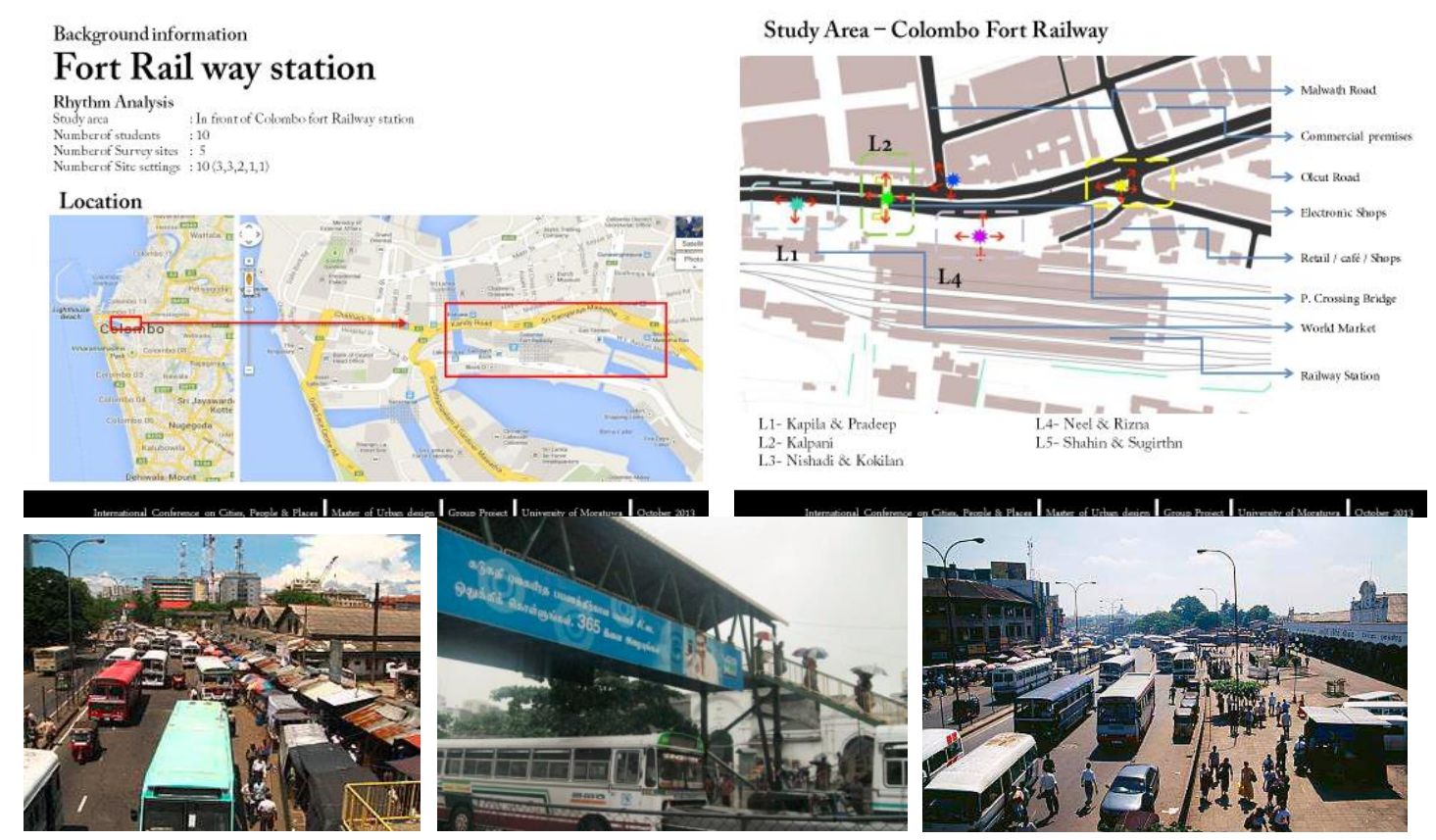

Fig. 6: Situation of fieldwork site and observation points around Fort Railway Station Source: Dr. Janaka Wijesundara and the fieldwork team of the University of Moratuwa

Fieldworkers chose to conduct fieldwork on a Sunday, when most travelers on an odd day off come to Colombo for shopping, sport or leisure events, or for visiting friends, relatives and loved ones. They identified five observation points in the immediate vicinity of the station and allocated each location to one group of fieldworkers. All groups agreed to make observations through time-lapse photography during two hours between 7:30 and 10.30 a.m. Cameras were turned in a number of directions at every location. These coordinated efforts resulted in a visual account of activities and flows of people as illustrated in Figure 7. 

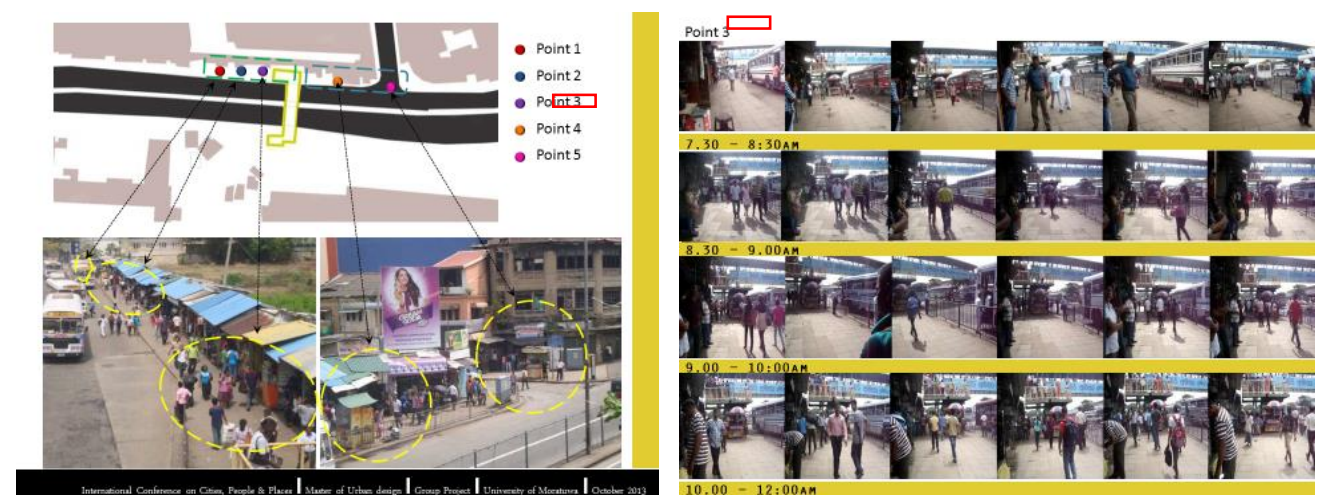

Fig. 7: Observation of the vicinity of Fort Station through time-lapse photography Source: Dr. Janaka Wijesundara and the fieldwork team of the University of Moratuwa

Given the size and complexity of the issues at stake here, workshop participants assigned to this case split up into three groups: one focused on the area in front of the station, another one on the footbridge across the road and the third one on the area at the opposite side of the road. In the course of the workshop the three groups came up with very similar lines of thought: the key issues they identified were bottlenecks to the flow of pedestrians and vehicles, as well as the lack of places devoid of any traffic. Examples of the first issue were the location of the bus-stop right at the footbridge and the confluence of pedestrians and customers of the road-side shops at the opposite side of the station. The second issue was apparent from the lack of shade and seating arrangements. As illustrated in Figure 8, the groups' design strategies concurred in converting the spaces on either side of the road into places of convergence (in front of the station) and dispersal (at the opposite side). To connect these two places, they proposed to create an underground pedestrian area that also would provide shops and resting areas.
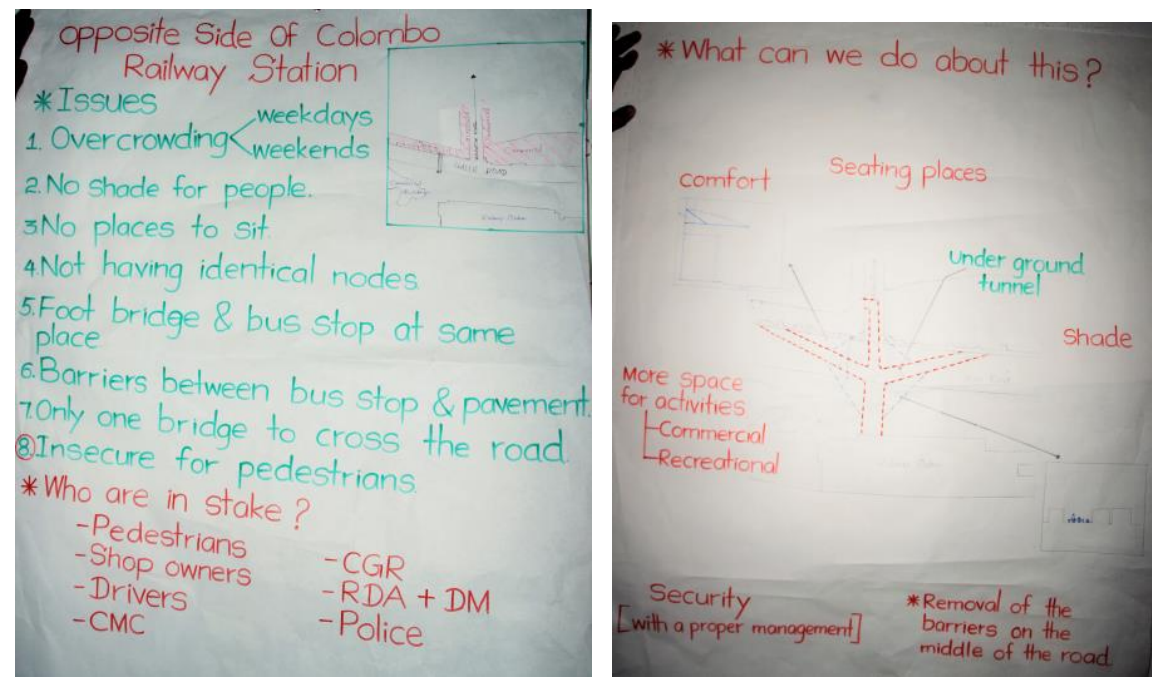

Fig. 8: Issues and design strategy elaborated for the Fort Railway Station Source: ICCPP2013 workshop participants 
International journal on Urban Environnements

\section{Lessons learnt and ways forward}

The idea for an ICCPP student workshop emerged as an afterthought while preparations for the first ICCPP conference were already underway. In view of the growing interest in temporality and tactical urbanism, organizers supported the idea to draw students' attention to time as a fourth dimension of architectural and urban design. The focus on rhythm-analysis grew out of a module that had taken several years to develop as part of semester-long course on Urban Anthropology. This module revolved around students' individual fieldwork: the entire process of preparation, data collection, fine-tuning of the initial findings, data-analysis and reporting took about one month.

The ICCPP workshop reduced the conceptual framework on rhythm-analysis and the methodological guidelines to a strict minimum. Partners willing to supervise students in anticipation of the workshop had to squeeze fieldwork in between other assignments. The workshop itself confronted students with new concepts and settings. Not only did they have to acquaint themselves with this context, but they also had to communicate with each other across differences in age, educational attainment and professional experience. Within the span of a few hours, they had to bridge these divides and come up with a coherent set of issues and design strategies. The workshop experiment thus became a learning experience for participants, coaches and organizers alike. Figure 9 summarizes the outcomes in terms of concept, method, logistics and learning process.

\begin{tabular}{|c|c|c|c|}
\hline Criteria & $\begin{array}{l}\text { Bophal } \\
\text { Nehru Nagar Junction }\end{array}$ & $\begin{array}{l}\text { New Dehli, Friends' Colony } \\
\text { Community Center }\end{array}$ & \begin{tabular}{|l|} 
Colombo \\
Fort Railway Station
\end{tabular} \\
\hline 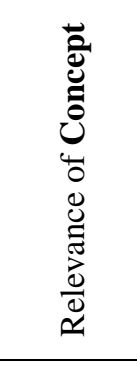 & $\begin{array}{l}\text { Diversification \& expansion } \\
\text { of market activities indicate } \\
\text { the potential of } \\
\text { rhythm-analysis as a research } \\
\text { tool because of the variance of } \\
\text { fixed and ambulant activities. } \\
\text { Case shows that the various } \\
\text { usages and users of the place } \\
\text { are in arrhythmia. }\end{array}$ & $\begin{array}{l}\text { Community centres often are } \\
\text { "required" components of } \\
\text { planned neighborhoods. } \\
\text { Case shows how dull \& } \\
\text { un-kept public spaces can be } \\
\text { when usual usages and users } \\
\text { are absent. }\end{array}$ & $\begin{array}{l}\text { A railway station offers ideal } \\
\text { opportunity to observe the } \\
\text { tension between regulated } \\
\text { time and natural rhythms. } \\
\text { The case demonstrates how } \\
\text { spatial obstructions inhibit a } \\
\text { balanced polyrhythmia of } \\
\text { usages and users' schedules }\end{array}$ \\
\hline 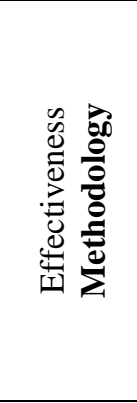 & $\begin{array}{l}\text { Identification of site and } \\
\text { observations give accurate } \\
\text { reflection of usages and users } \\
\text { on the site. } \\
\text { Shortage of information on } \\
\text { nature of / linkages with the } \\
\text { residential areas behind the } \\
\text { market \& shophouses makes } \\
\text { design strategy hypothetical. }\end{array}$ & $\begin{array}{l}\text { Fieldworkers gave added } \\
\text { value to 'lived experience' by } \\
\text { notes on atmosphere and } \\
\text { moods. } \\
\text { Shortage of information on } \\
\text { users and usages on weekdays } \\
\text { proves a drawback for } \\
\text { devising design strategy. }\end{array}$ & $\begin{array}{l}\text { Fieldwork gives a systematic } \\
\& \text { well-organized overview of } \\
\text { the site. Various perspectives } \\
\text { rendered in clear visual way. } \\
\text { Observation time limited to } \\
\text { one segment of the day on } \\
\text { weekly day-off. } \\
\text { Additional information about } \\
\text { usages \& users on weekdays } \\
\text { would have been useful. }\end{array}$ \\
\hline
\end{tabular}




\begin{tabular}{|c|c|c|c|}
\hline 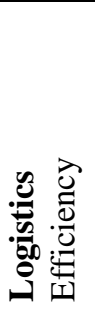 & $\begin{array}{l}\text { Contact with S.P.A. } \\
\text { supervisor started late and } \\
\text { confirmation of only } 5 \\
\text { fieldworkers. } \\
\text { Students could not join the } \\
\text { workshop with supervisor. }\end{array}$ & $\begin{array}{l}\text { Contact with S.P.A. } \\
\text { supervisor made timely } \\
\text { selection of site and } 9 \\
\text { fieldworkers possible. } \\
\text { Study loads force them to } \\
\text { conduct fieldwork on Sunday. } \\
\text { Only } 1 \text { student could join the } \\
\text { supervisor at the workshop. }\end{array}$ & $\begin{array}{l}10 \text { MUD students under close } \\
\text { supervision conduct fieldwork } \\
\text { and prepare workshop } \\
\text { logistics. } \\
\text { Work \& study commitments } \\
\text { force them to conduct } \\
\text { fieldwork on Sunday }\end{array}$ \\
\hline 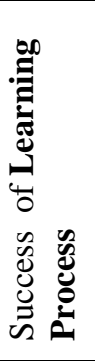 & $\begin{array}{l}\text { Fieldworkers' learning curve } \\
\text { remains incomplete due to } \\
\text { absence at the workshop. } \\
\text { Workshop participants enjoy } \\
\text { exposure to the unfamiliar } \\
\text { context of Bophal but their } \\
\text { intercultural learning is } \\
\text { limited to exchanges with } \\
\text { supervisors and coaches. }\end{array}$ & $\begin{array}{l}\text { The majority of fieldworkers } \\
\text { cannot attend the workshop } \\
\text { after fieldwork. } \\
\text { Workshop participants enjoy } \\
\text { exposure to the unfamiliar } \\
\text { context of New Dehli but their } \\
\text { intercultural learning is } \\
\text { limited to exchanges with } \\
\text { supervisors and coaches. }\end{array}$ & $\begin{array}{l}\text { Fieldworkers and workshop } \\
\text { participants both get to know } \\
\text { more about the fieldwork site } \\
\text { in Colombo. They can benefit } \\
\text { from the workshop dynamics, } \\
\text { but intercultural learning is } \\
\text { limited to exchanges with } \\
\text { supervisors and coaches. }\end{array}$ \\
\hline
\end{tabular}

Fig. 9: Summary assessment of the ICCPP 2013 workshop outcomes Source: Author

This summary assessment clearly indicates that this first-time experiment ran into several flaws and limitations. It also points out that organizers, their academic partners as well as student participants showed resourcefulness and determination throughout this initiative. Hence, it is useful to draw up lessons to take forward to further editions of the workshop (Figure 10).

\begin{tabular}{|l|l|l|}
\hline Criteria & \multicolumn{1}{c|}{ Lessons to take forward } \\
\hline & $\begin{array}{l}\text { The focus on rhythmanalysis emerged from a research interest external to the ICCPP } \\
\text { conference initiative. In the future, workshop themes should link up more closely to the } \\
\text { overall conference theme. } \\
\text { The pre-workshop activities ideally should be integrated as part of a course or design at } \\
\text { the home university of the fieldworkers his would benefit time-management as well the } \\
\text { motivation and learning curve of students who sacrifice time, resources and energy in the } \\
\text { fieldwork. }\end{array}$ \\
\hline$>\begin{array}{l}\text { Methodological guidelines for fieldworkers should emphasize the need to provide } \\
\text { background information on the wider spatial setting of the fieldwork site as well on the } \\
\text { variations of usages and users at other times than the detailed fieldwork observation. }\end{array}$ \\
\hline $\begin{array}{l}\text { Workshop participants should receive a clear introduction to the envisaged dynamics and } \\
\text { expected results. }\end{array}$ \\
\hline $\begin{array}{l}\text { Identification of interested partners and communication on the workshop theme, } \\
\text { conceptual framework and methodological guidelines should be arranged well in } \\
\text { advance so that supervisors and students have time to identify a site and organize } \\
\text { fieldwork. This also offers a greater chance that fieldworkers can organize the required } \\
\text { documents and resources to attend the workshop. }\end{array}$ \\
\hline
\end{tabular}




\begin{tabular}{|c|c|}
\hline 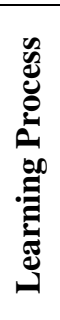 & $\begin{array}{l}\text { The concept of transdisciplinary learning undeniably added value to the workshop and } \\
\text { should further be emphasized given the context of rapid urbanization and disaster } \\
\text { proneness that mark most countries in Asia. } \\
\text { The interactive dynamics devised for the workshop proved efficient and should be } \\
\text { further refined, possibly spreading the process over more than one day. } \\
\text { The workshop organizers should strive to attract a greater cultural and disciplinary } \\
\text { diversity of fieldworkers and workshop participants, so that students benefit all the more } \\
\text { from intercultural learning. }\end{array}$ \\
\hline
\end{tabular}

Fig. 10: lessons learnt and ways forward Source: Author

By the time this paper is published, a second ICCPP workshop has been organized and a third one is in the making. In the course of this journey, cooperation between the Faculty of Architecture at UoM and at KUL have been consolidated and new partnerships explored. Underlying this process, is a common endeavor to encourage students to get to know other settings and contexts, but also get the time to get to know and value one another face-to-face outside the classroom. Exposure and intercultural learning might well be the greatest achievement reached in this workshop. It deserves further development.

\section{Acknowledgements}

The workshop was conducted under the chairmanship of Dr. Janaka Wijesundara at the Department of Architecture of the University of Moratuwa. It was prepared and conducted by Dr. Koen De Wandeler (KU Leuven) with the assistance of Mr. Asiri Dissanayake (Int'1 M.Arch. student at KU Leuven in 2013 and lecturer at UoM in 2014) and Mr. Sugirthan Kumaraguru (MUD student at UoM). Dr. Frank Schwartze (LUAS, Lubeck University of Applied Sciences, Germany), Dr. Samuel Hammer (University of Boston, USA), Prof. Dr. Ranjana Mittal (S.P.A. New Dehli, India) and Asst.Prof. Supriya Kukreya (S.P.A. Bhopal, India) coached students' progress throughout the workshop in 2013. Over eighty bachelor and master students attended each of these workshop: their enthusiastic drive greatly contributed to the success of both events.

\section{References}

Bauman, Z. (2000) Liquid Modernity, Oxford: Blackwell.

Bishop, P. and Williams, L. (2012) The Temporary City. London/New York: Routledge.

Doucet, I. and Janssens, N. (eds.) (2011) 'Editorial: Transdiciplinarity, The Hybridisation of Knowledge Production and Space-Related Research' in Transdisciplinary Knowledge Production in Architecture and Urbanism: Towards Hybrid Modes of Inquiry (Urban and Landscape Perspectives), Heidelberg: Springer.

Highmore, B. (2005) Cityscapes: Cultural Readings in the Material and Symbolic City, Basingstoke/ New York: Palgrave Macmillan.

Hirsch Hadorn, G. et al. (eds.) (2008) Handbook of transdisciplinary research. Heidelberg: Springer.

Jahn, T., M. Bergmann, F. Keil, (2012), 'Transdisciplinarity: between mainstreaming and marginalization', Ecological Economics, Volume 79, July 2012, pp 1-10.

Lefebvre, H. (1995 [1962]) Introduction to Modernity: Twelve Preludes (Transl.: John Moore), London: Verso. 
International journal on Urban Environnements

Lefebvre, H. (2004 [1992]), Rhythmanalysis: Space, Time and Everyday Life (Transl. Stuart Elden and Gerald Moore), London-New York: Continuum.

Marsh, Peter (2013), The New Industrial Revolution: Consumers, Globalization and the End of Mass Production, Yale University Press, USA.

Marsh, Peter (2014), http://petermarsh.eu/the-new-industrial-revolution-all-is-explained/ [Accesssed 20 June 2015]

Urban Catalyst (2007) Urban Pioneers: Temporary Use and Urban Development in Berlin. Berlin: Jovis. 